\title{
$\begin{array}{lllllllll}\text { I } & \mathrm{N} & \mathrm{S} & \mathrm{T} & \mathrm{I} & \mathrm{T} & \mathrm{U} & \mathrm{T} & \mathrm{E}\end{array}$
}

\section{Home Care Workers: Keeping Granite Staters in Their Homes as They Age}

KR I S T I N SM I T H

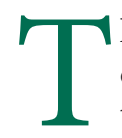

he question of how to provide necessary health care and personal services to a growing population over age 65 is an urgent policy problem facing New Hampshire and the nation. With the aging baby boom generation, the New Hampshire population over the age of 65 is growing twice as fast as the total population, ${ }^{1}$ and today 13 percent of the state's population is age 65 or older, up from 11 percent in $1990 .{ }^{2}$ Research shows that the population over 65 in New Hampshire prefers to remain in their own homes and receive home-based care rather than reside in a nursing home or an assisted living facility. ${ }^{3}$ There is evidence suggesting that home-based care may be more cost effective than institutional care, as states with established home and community-based services (HCBS) experienced cost savings in Medicaid spending over time. ${ }^{4}$ In response to the preference for home-based care among older adults and people with disabilities and the potential for cost savings, the state of New Hampshire has supported the expansion of the HCBS system and increased Medicaid funding for homebased services. ${ }^{5}$

The growing older population and their desire to remain in their homes coupled with increased funding for homebased services translates into increased demand for the services the home care workforce provide. In fact, the New Hampshire Department of Employment Security projects that between 2006 and 2016, "home health aide" will be the fastest growing occupation, highlighting the demand and preference for home-based care. ${ }^{6}$ Yet, despite the growth of the home care workforce in New Hampshire, the demand for home care workers outpaces the supply. New Hampshire is just not keeping up with the rising demand.

High turnover rates are common among the home care workforce. The majority of direct care employers in New Hampshire agree that turnover is a problem and state that they need to hire one or more home care workers to meet current service demands. High turnover in this workforce contributes to lower-quality care. Furthermore, research

\section{Key Findings:}

- The median hourly wage for home care workers in New Hampshire is $\$ 10.00$, whereas the median hourly wage for all New Hampshire workers is $\$ 16.48$. LNAs earn the highest median hourly wage, at $\$ 11.77$ per hour, almost $\$ 2.00$ more per hour than PCSPs and almost $\$ 3.00$ more per hour than homemakers.

- Twenty-nine percent of home care workers in New Hampshire typically work full-time hours for their home care agency. By cobbling together part-time jobs, 46 percent attain full-time hours, but they lack benefits and face a wage disadvantage compared with those who have fulltime hours at their home care agency.

- One-third of home care workers in New Hampshire lack health insurance, primarily because it is too expensive for the employees.

- More than half of home care workers are covered by health insurance through a private sector provider; fewer than one in five home care workers are covered by health insurance through their direct care employer.

- Very few home care workers receive paid time off; in fact, 67 percent have no paid leave of any kind. Full-time workers are twice as likely to have paid leave as part-time workers.

- Home care workers were asked to name all the features that would make their job better. Higher wages was the leading factor, followed by better access to benefits, such as health insurance, more paid time off, and more opportunities for advancement. 
using national data shows that those who work in direct care occupations face a wage penalty; that is, they earn less than expected given their job characteristics and qualifications. ${ }^{7}$ Low wages, unstable work hours, and limited benefits contribute to high turnover among this workforce. ${ }^{8}$

Many in the Granite State are considering strategies to address the shortage of home care workers. To inform these discussions, the Carsey Institute at the University of New Hampshire was asked by the New Hampshire Institute for Health Policy and Practice to assist with the development, administration, and analyses of a survey of the home care workforce and their employers in order to profile the workforce and examine wages, benefits, and retention. The results from this New Hampshire Direct Care Workforce Survey are presented in this brief (see the Data section at the end of this brief for more information about the data collection effort).

This policy brief provides a demographic and economic profile of the current home care workforce in New Hampshire, which includes licensed nursing assistants (LNA), personal care service providers (PCSP), personal care assistants (PCA), and homemakers and companions. The profile includes home care workers who work for agencies that provide home- and community-based services and receive reimbursement from Medicaid, Medicare, and other federal and state-funded programs. The final section of the brief discusses the potential implications of low pay and high turnover for long-term care among older adults and people with disabilities in New Hampshire.

\section{Types of Home Care Workers}

Direct care workers (of which home care workers are one type) provide the majority of paid, hands-on care, supervision, and emotional support to older adults and persons with disabilities in the United States. These paraprofessionals hold a variety of job titles, including licensed nursing assistant (LNA), personal care service provider (PCSP), personal care assistant (PCA), home care aide, home health aide, homemaker, and companion. They work in diverse settings, including private homes, adult day centers, assisted-living residences, hospitals, and nursing homes. Depending on their job title and the setting, a direct care worker's tasks may include assistance with medications and measuring vital signs; assisting with personal care activities, such as bathing, dressing, using the toilet, and eating; providing comfort and companionship; and shopping, preparing meals, and cleaning the house. ${ }^{9}$

Workers described in this brief provide either hands-on care, light housekeeping, support, or companionship. In 2008, 59 percent of Granite State home care workers were PCSPs or PCAs (which in the remainder of the brief we
Figure 1. JOB TITLE, HOME CARE WORKERS, NH 2008

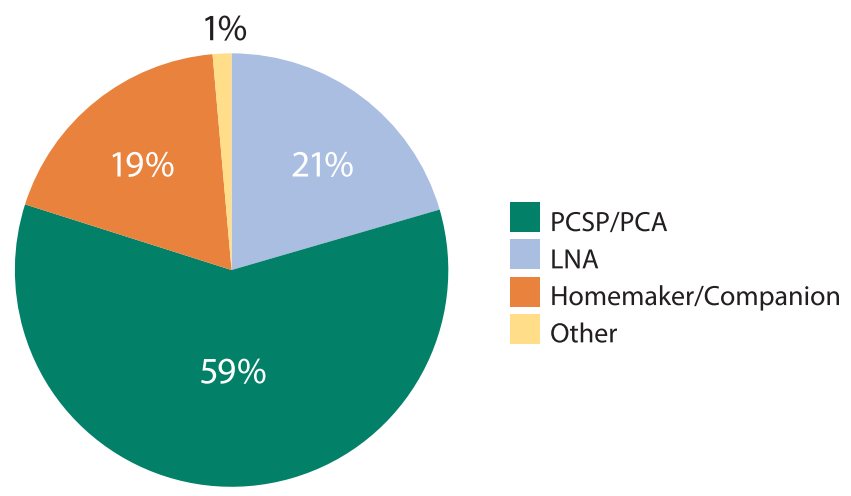

refer to as PCSPs), 21 percent were LNAs, and 19 percent were homemaker/companions (which in the remainder of the brief we refer to as homemakers) (see Figure 1). In New Hampshire, both LNAs and PCSPs help clients with activities of daily living, including bathing, dressing, using the toilet, and eating. LNAs are licensed and supervised by a nurse, and they also perform clinical tasks, such as range-ofmotion exercises, blood pressure readings, and can assist with administering medication if they complete extra training beyond the mandated 100 hours. ${ }^{10}$ Homemakers provide light housekeeping, such as shopping, doing laundry, preparing meals, cleaning the house, and providing comfort and companionship. PCSPs often will help with housekeeping chores as well and are required to complete 10 hours of training. (Refer to the NH Coalition for the Direct Care Workforce, endnote 5, for more information on the home care workforce.)

\section{The Home Care Workforce in New Hampshire}

The New Hampshire home care workforce is predominantly female (90 percent) (see Table 1). This workforce is also older (on average, 48 years old) than the state's workforce overall, which is on average 41 years old. Homemakers tend to be older than PCSPs and LNAs. The majority of home care workers are married (58 percent), and one-third have children under 18 living with them. Only 11 percent are single mothers.

Nearly one-half of the home care workforce has a high school degree or less. However, LNAs tend to have more education than PCSPs or homemakers. Two-thirds of LNAs have some college or more, compared with roughly one-half of PCSPs and homemakers. Only one-third of LNAs have 
TABle 1. Demographic CHARACTERISTICS OF HOME CARE WORKERS, NH 2008

\begin{tabular}{|c|c|c|c|c|}
\hline & \multirow[b]{2}{*}{ All } & \multicolumn{3}{|c|}{ JOB TITLE } \\
\hline & & LNA & PCSP & Homemaker \\
\hline Female & 90 & 99 & 85 & 94 \\
\hline Average age & 48 & 45 & 47 & 52 \\
\hline \multicolumn{5}{|l|}{ Marital status } \\
\hline Married or cohabiting & 58 & 55 & 60 & 59 \\
\hline Previously married & 26 & 23 & 26 & 26 \\
\hline Never married & 16 & 23 & 14 & 15 \\
\hline Child under 18 & 33 & 39 & 33 & 26 \\
\hline Single mother & 11 & 16 & 9 & 9 \\
\hline Married mother & 22 & 22 & 24 & 17 \\
\hline \multicolumn{5}{|l|}{ Education } \\
\hline High school or less & 47 & 34 & 50 & 53 \\
\hline Some college & 40 & 57 & 36 & 36 \\
\hline College graduate & 13 & 10 & 14 & 11 \\
\hline \multicolumn{5}{|l|}{ Total family income } \\
\hline Less than $\$ 20,000$ & 30 & 23 & 30 & 42 \\
\hline$\$ 20,000-\$ 29,999$ & 22 & 23 & 22 & 16 \\
\hline$\$ 30,000-\$ 39,999$ & 14 & 14 & 15 & 14 \\
\hline$\$ 40,000-\$ 49,999$ & 14 & 18 & 14 & 11 \\
\hline$\$ 50,000$ or more & 19 & 22 & 19 & 17 \\
\hline
\end{tabular}

Source: NH Direct Care Workforce Survey, 2008.

Note: All numbers are percentages unless otherwise noted.

"What I do makes a difference in other people's lives. That's the most important thing to me."

-Homemaker, 19-year-old single mother

a high school degree or less, while one-half of PCSPs and homemakers do.

More than one-half of home care workers have family incomes of less than $\$ 30,000$ annually. Homemakers fare the worst economically: 42 percent have family incomes of less than $\$ 20,000$ annually. In contrast, 23 percent of LNAs and only 4 percent of the state's workers overall report family incomes this low. Further, one-half of single home care workers live on less than $\$ 20,000$ annually. Despite the low pay, many cite the rewards of the job as reasons for continuing. One worker sums it up for many: "What I do makes a difference in other people's lives. That's the most important thing to me."
Table 2. Job Characteristics of Home Care WORKERS, NH 2008

\begin{tabular}{|c|c|c|c|c|}
\hline & & & JOB TIT & \\
\hline & All & LNA & PCSP & Homemaker \\
\hline Hours work & & & & \\
\hline Full-time (35 or more) & 29 & 40 & 29 & 19 \\
\hline Average hours & 24 & 27 & 24 & 22 \\
\hline More than one job & 41 & 51 & 41 & 29 \\
\hline Full-time at all jobs & 46 & 58 & 47 & 30 \\
\hline Average hours at all jobs & 33 & 37 & 33 & 27 \\
\hline Number of clients & & & & \\
\hline 1 & 53 & 24 & 71 & 23 \\
\hline $2-5$ & 29 & 37 & 25 & 32 \\
\hline 6 or more & 18 & 39 & 4 & 46 \\
\hline Care for: & & & & \\
\hline Family & 18 & 10 & 23 & 12 \\
\hline Friend & 17 & 12 & 21 & 6 \\
\hline Previously unknown & 65 & 81 & 58 & 70 \\
\hline
\end{tabular}

\section{Employer size}

Less than 20 employees $\quad 6 \quad 18 \quad 5$

$\begin{array}{lllll}20-100 \text { employees } & 25 & 32 & 13 & 57\end{array}$

More than 100 employees $\quad 69 \quad 50 \quad 86 \quad 39$

Time worked with agency

$\begin{array}{lllll}\text { Less than } 6 \text { months } & 22 & 20 & 22 & 21 \\ 6-11 \text { months } & 12 & 13 & 11 & 13 \\ 12-23 \text { months } & 16 & 13 & 16 & 14 \\ 24-35 \text { months } & 14 & 10 & 17 & 9 \\ 36 \text { or more months } & 37 & 45 & 34 & 43 \\ \text { Average months } & 41 & 57 & 33 & 52\end{array}$

\section{Shifts worked}

$\begin{array}{lllll}\text { Days } & 89 & 92 & 85 & 95\end{array}$

$\begin{array}{lllll}\text { Weekends } & 44 & 54 & 50 & 15\end{array}$

Nights

$30 \quad 30$

Source: NH Direct Care Workforce Survey, 2008.

Note: All numbers are percentages unless otherwise noted.

\section{Job Characteristics}

Most PCSPs provide services to only one person (see Table 2). Large proportions of homemakers, however, provide services to six or more people. This variation in number of clients likely derives from differences between consumer-directed models and agency-directed models. In consumer-directed models, the person receiving care typically knows the home care worker (usually a PCSP), as many are family members, friends, or neighbors. In con- 
trast, in agency-directed models, the agency is responsible for scheduling workers and typically hires all three types of workers to care for clients, who generally are previously unknown to the worker. ${ }^{11}$

Despite desiring more hours, fewer than one-third of home care workers work full-time hours (35 or more) in a typical week. On average, they work 24 hours per week. Although 40 percent of LNAs work full-time, only 19 percent of homemakers do. To make up for this lack of full-time work, many work more than one job. By cobbling together part-time jobs, 46 percent of home care workers attain fulltime hours, but as we will show, they lack benefits and face a wage disadvantage compared with those who have full-time hours at their home care agency.

Some people require care around the clock, including weekends. Many home care workers are working nonstandard hours. Forty-four percent regularly work weekends and 30 percent regularly work nights. It is common for home care workers to combine shifts, working days and weekends or days and nights, and about one in five work all three shifts. Even though days are the most common shift across job type, large proportions of LNAs and PCSPs work all three shifts regularly. In contrast, homemakers tend to work days only and rarely work weekends or nights.

One-fifth of home care workers have been with their agency for fewer than six months, but on average workers have been with their agency for 41 months. LNAs have the longest tenure with their agency ( 57 months), followed by homemakers (52 months), and PCSPs (33 months). On average, full-time workers have been with their agency longer than part-time workers (66 months compared with 31 months).

The majority work for large agencies with 100 or more employees, driven primarily by the large agencies that primarily employ PCSPs. However, 6 percent work for small agencies (fewer than twenty employees). Fully 86 percent of PCSPs work for a large agency, compared with 50 percent of LNAs and 39 percent of homemakers. Seventy-one percent of part-timers work for a large agency.

New Hampshire's home care workforce work for established agencies; 68 percent have been in existence for 20 or more years. More than one-half are private, not-forprofit agencies; one-quarter are private, for-profit agencies; and the remainder are publicly owned or part of a hospital or health system.

\section{Wages}

The median hourly wage for home care workers in New Hampshire is $\$ 10$ (see Table 3). ${ }^{12}$ Although higher than the state minimum wage of $\$ 7.25$ per hour, it falls short of the 2008 livable wage needed to cover basic expenses for a single person (\$11.55), for a dual-earner married couple with two
TABle 3. WAges PAID TO HOME CARE WORKERS, NH 2008

\begin{tabular}{lc}
\hline & MEDIAN HOURLY WAGE \\
\hline Total & $\$ 10.00$ \\
\hline Job title & \\
LNA & $\$ 11.77$ \\
PCSP & $\$ 10.00$ \\
Homemaker & $\$ 8.98$ \\
\hline Education & \\
High school or less & $\$ 10.00$ \\
Some college & $\$ 10.00$ \\
College graduate & $\$ 10.00$ \\
\hline Region & \\
Northern & $\$ 9.75$ \\
Western & $\$ 10.00$ \\
Central & $\$ 10.00$ \\
Hillsborough & $\$ 10.00$ \\
Seacoast & $\$ 10.00$ \\
- Hours worked per week & $\$ 10.00$ \\
Full-time & $\$ 10.00$ \\
Part-time & $\$ 10.25$ \\
\hline Shift worked & $\$ 10.000$ \\
Day & $\$ 10.00$ \\
Weekend & \\
Night & \\
Day only & \\
Weekend only & \\
Night only & \\
\hline & \\
Source & \\
\hline
\end{tabular}

Source: NH Direct Care Workforce Survey, 2008.

Figure 2. Distribution of hourly WAgE By JOB TITLE, NH 2008

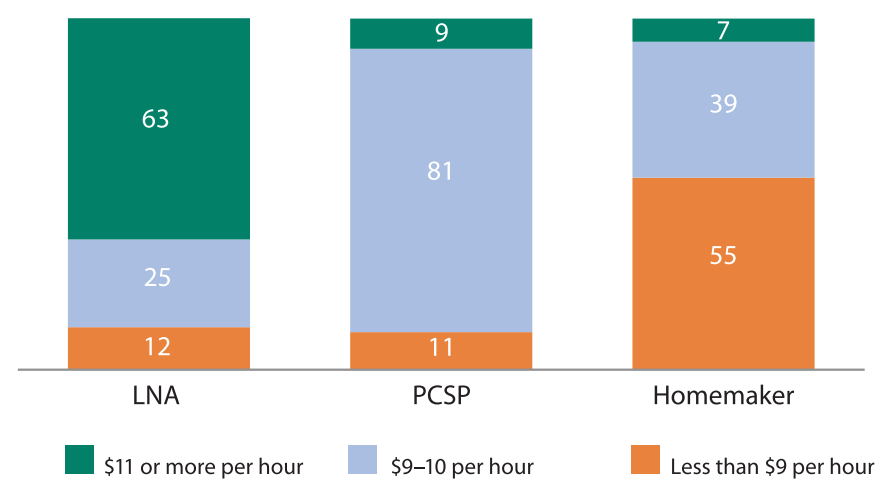


Figure 3. MEDIAN WAGE BY TIME SPENT WORKING WITH CURRENT DIRECT CARE AGENCY, NH 2008

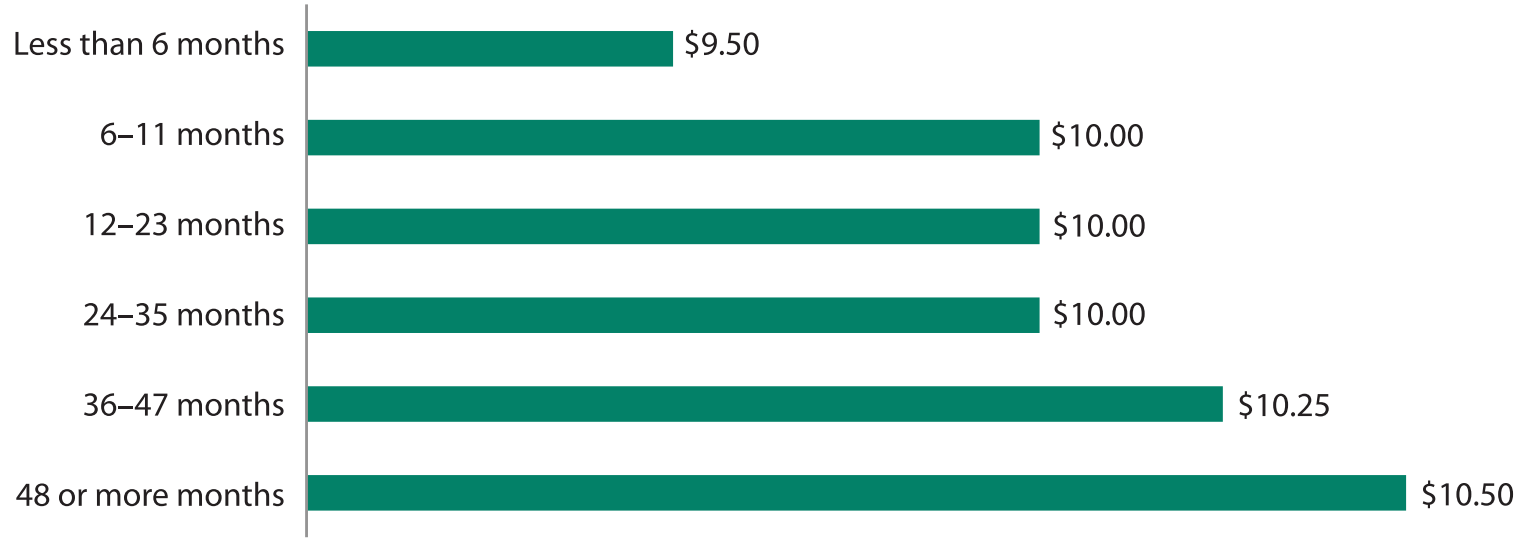

children (both would need to earn \$12.19), and for a single mother with one child (\$17.68). ${ }^{13}$ The median hourly wage for all New Hampshire workers is $\$ 16.48$.

Full-time home care workers earn $\$ 10.25$ per hour, or $\$ 20,500$ for a full-time, year-round position. ${ }^{14}$ The median annual salary of New Hampshire full-time workers is $\$ 40,000$. Home care workers commonly cited better pay as a factor that would make their job better: "It's hard to pay the bills. If I wasn't on Social Security, I couldn't afford to work at this job."

\section{“Better pay would improve my job. It's hard to pay the bills. If I wasn't on Social Security, I couldn't afford to work at this job." \\ -Homemaker, 63-year-old part-time worker}

LNAs earn the highest median hourly wage, at $\$ 11.77$ per hour, almost \$2.00 more per hour than PCSPs and almost $\$ 3.00$ more per hour than homemakers. Even larger discrepancies appear when examining the distribution of wages (see Figure 2). Fully 63 percent of LNAs earn $\$ 11$ or more per hour, a far greater proportion than the 9 percent of PCSPs or the 7 percent of homemakers. Hourly wages for PCSPs are relatively uniform, with 81 percent earning between $\$ 9$ and $\$ 10$ per hour.

Typically in jobs, median earnings increase with education, but this is not the case with home care workers in New Hampshire. Median hourly wages (the wage at which half of all workers earn more and half earn less) are \$10 per hour regardless of education. However, when looking behind the median levels, home care workers with more than a high school degree are more than twice as likely to earn $\$ 11$ or more (26 percent) than those who have less education (12 percent).

Reimbursement levels for services may determine wages, particularly among agencies that rely on Medicaid reimbursement. This, some argue, works as a cap on wages. Recall that home care workers with some college education were more likely to work as LNAs, who receive higher wages and may perform services that reimburse at higher levels.

Home care workers living in the North Country earn \$.25 less per hour than their colleagues in other regions of New Hampshire. This amounts to a \$520 annual earnings disadvantage for northern full-time, year-round workers. Another important factor that influences wages is the number of hours worked per week. Full-time workers earn, on average, \$.25 more per hour than those who work fewer than 35 hours per week for the agency. More full-time workers earn $\$ 11$ or more per hour than part-time workers (36 percent and 13 percent, respectively). Workers earn, on average, $\$ .25$ more per hour for working nonstandard hours but just for the 4 percent who only work the night shift.

Earnings also increase modestly with time spent working for the agency (see Figure 3). In fact, 84 percent of agencies report that they have scheduled wage increases, which rewards tenure. For example, workers who have been with their agency for fewer than six months earn $\$ 9.50$ per hour. Once they have passed the six-month mark, they get a pay increase to $\$ 10.00$ per hour. Not until workers pass their three-year anniversary with the same agency do they see another pay raise, to $\$ 10.25$ per hour. Finally, workers who have stayed with their agency for four or more years earn a median hourly wage of $\$ 10.50$. This represents an increase of $\$ 1.00$ per hour in four years. 


\section{Benefits}

\section{Health Insurance}

Ironically, one-third of home care workers in New Hampshire lack health insurance (see Table 4), which is higher than all female workers in New Hampshire (16 percent). ${ }^{15}$ The principal reason given for not having health insurance coverage is that it is too expensive (see Figure 4 ). The average cost per month for individual coverage for a full-time worker is $\$ 91$, while the monthly employer contribution is $\$ 357$ (see Figure 5). The cost rises sharply when considering family coverage for a full-time worker: the average monthly employee contribution is $\$ 613$ and the employer contribution is $\$ 727$. Considering that home care workers earn $\$ 10$ per hour, these monthly contributions are likely out of reach, especially since this cost does not include any deductible or cost sharing that many health insurance plans require. One home care worker comments, "Having affordable health insurance would improve my job. Our health insurance has a rather high deductible."

Other reasons given among home care workers for not having health insurance are that the employer does not offer health insurance or the workers are ineligible. Nearly three-fourths (74 percent) of employers report that they offer health insurance to their direct care staff, but many base eligibility on time spent at the agency and minimum hours per week (that is, they offer insurance only to full-time employees). For example, 48 percent offer health insurance to workers after three months on the job; 7 percent require two months, 32 percent require one month, and 13 percent do not have a waiting period. Although a wide range exists regarding the required minimum hours worked per week to be eligible for health insurance (from 15 to 40 hours), on average, employers require 30 hours per week. Since many workers desire full-time hours but do not get it from their direct care employer, these workers are doubly disadvantaged: their overall take-home pay is lower, unless they seek a second job, but due to their part-time status, they are not eligible for health insurance benefits.

\section{"Having affordable health insurance would improve my job. Our health insurance has a rather high deductible." \\ -LNA, 23-year-old full-time worker}

PCSPs are more likely to lack health insurance (40 percent) compared with LNAs and homemakers (30 percent and 21 percent, respectively). Twenty-two percent of homemakers rely on public health insurance. Working in a large

TABle 4. Health insurance COVERAge AND PAID leave Benefits AMONG home CARE WORKERS, NH 2008

\begin{tabular}{|c|c|c|c|c|c|c|c|c|c|c|}
\hline & \multicolumn{4}{|c|}{ JOB TITLE } & \multicolumn{2}{|c|}{ HOURS WORKED } & \multicolumn{2}{|c|}{$\begin{array}{l}\text { NUMBER OF } \\
\text { EMPLOYEES }\end{array}$} & \multicolumn{2}{|c|}{$\begin{array}{c}\text { TIME SPENT } \\
\text { WITH AGENCY }\end{array}$} \\
\hline & ALL & LNA & PCSP & Homemaker & Full-time & Part-time & $\begin{array}{l}\text { Less than } \\
100\end{array}$ & $\begin{array}{c}100 \\
\text { or more }\end{array}$ & $\begin{array}{l}\text { Less than } \\
3 \text { years }\end{array}$ & $\begin{array}{c}3 \text { or } \\
\text { more years }\end{array}$ \\
\hline \multicolumn{11}{|l|}{ Health insurance coverage } \\
\hline Private sector & 53 & 62 & 47 & 61 & 58 & 51 & 58 & 51 & 48 & 61 \\
\hline Direct care employer & 19 & 38 & 13 & 16 & 52 & 6 & 24 & 16 & 12 & 30 \\
\hline Spouse's employer & 34 & 30 & 36 & 35 & 22 & 39 & 35 & 34 & 33 & 35 \\
\hline Public sector & 16 & 10 & 17 & 22 & 7 & 20 & 20 & 15 & 17 & 15 \\
\hline No health insurance & 34 & 30 & 40 & 21 & 36 & 33 & 26 & 38 & 38 & 28 \\
\hline \multicolumn{11}{|l|}{ Paid leave benefits } \\
\hline Paid sick leave & 13 & 25 & 7 & 19 & 28 & 6 & 18 & 10 & 7 & 22 \\
\hline Paid vacation leave & 15 & 32 & 7 & 24 & 30 & 10 & 23 & 12 & 9 & 26 \\
\hline Paid holidays & 18 & 31 & 10 & 30 & 31 & 12 & 28 & 13 & 12 & 28 \\
\hline Earned time & 22 & 45 & 10 & 40 & 36 & 17 & 43 & 13 & 17 & 30 \\
\hline One or more types of paid leave & 33 & 64 & 15 & 59 & 53 & 24 & 59 & 21 & 24 & 47 \\
\hline
\end{tabular}

Source: NH Direct Care Workforce Survey, 2008.

Note: All numbers are percentages. 
FIgURE 4. REASONS HOME CARE WORKERS LACK HEALTH INSURANCE, NH 2008

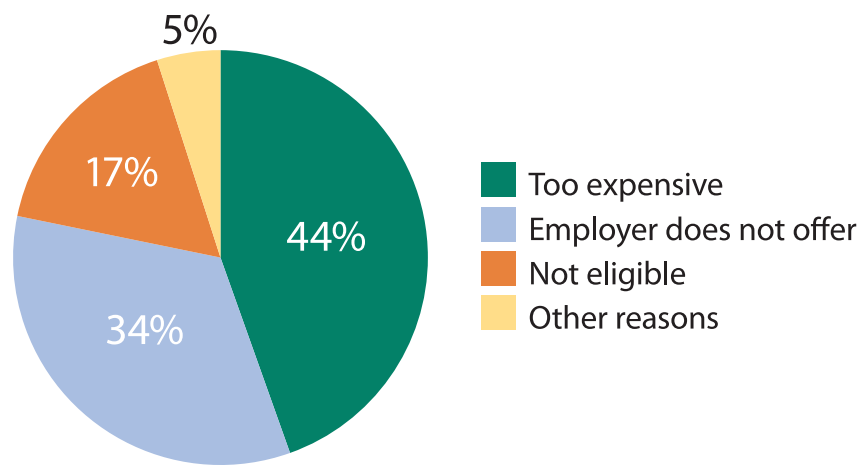

agency (100 or more employees) and working for an agency for fewer than three years both increase the likelihood of lacking health insurance.

More than half of home care workers are covered by health insurance through a private sector provider (see Table 4). Yet, fewer than one in five home care workers are covered by health insurance through their direct care employer. LNAs are more likely to have health insurance through their employer than PCSPs or homemakers, as are full-time workers. More than half of full-time workers, but only 6 percent of part-time workers, are covered through their direct care employer. Home care workers who have worked with their employer for more than three years are more likely to have health insurance through their employer than are those who have worked less time (30 percent compared with 12 percent). It is more common for home care workers to be covered by health insurance through their spouse or partner's employer than their own.

\section{Paid Leave}

Very few home care workers receive paid time off, either paid sick leave (13 percent), paid vacation (15 percent), paid holidays (18 percent), or earned time (22 percent) (see Table 4). Only one-third of workers have at least one of these types of paid leave options. The lack of paid time off translates into not taking time off for many home care workers. As one worker aptly puts it, "I haven't had a vacation in seven years because I can't afford to take the time off."
FIGURE 5. MONTHLY EMPLOYEE AND EMPLOYER CONTRIBUTIONS TO HEALTH INSURANCE PREMIUMS FOR FULL-TIME HOME CARE WORKERS, NH 2008

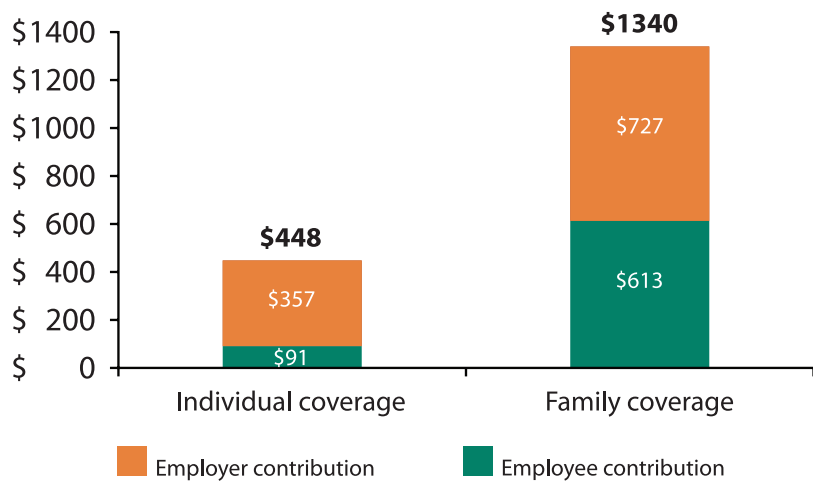

"I haven't had a vacation in seven years because I can't afford to take the time off."

-PCSP, 49-year-old full-time worker

Many of the same predictors of health insurance apply to paid leave. Full-time workers are twice as likely to have paid leave than part-time workers. Nearly 60 percent of workers with a smaller agency (fewer than 100 employees) and nearly one-half who have worked with their employer for three or more years receive some paid time off. LNAs are much more likely to have some type of paid leave than PCSPs. Contrary to the patterns with health insurance, however, nearly 60 percent of homemakers, who are not likely to receive health insurance through their employer, do receive some paid leave.

\section{Job Satisfaction}

Home care workers were asked to name all the features that would make their job better. Not surprisingly, higher wages was the leading factor (see Figure 6). Better access to benefits, such as health insurance, was the second most popular factor, followed by more paid time off and more opportunities for advancement. A greater share of LNAs preferred more opportunities for advancement than PCSPs or homemakers.

Workers travel from client to client, typically in their own vehicle. Many commented on the high cost of gas (the survey was conducted during the summer of 2008, when gas prices reached record highs and the economy was in recession). Many, therefore, would like to be reimbursed for mileage or receive higher rates of reimbursement. Over eight in ten agencies provide mileage reimbursement. The federal 
FiguRE 6. FACTORS HOME HEALTH CARE WORKERS STATE WOULD IMPROVE THEIR JOB, NH 2008

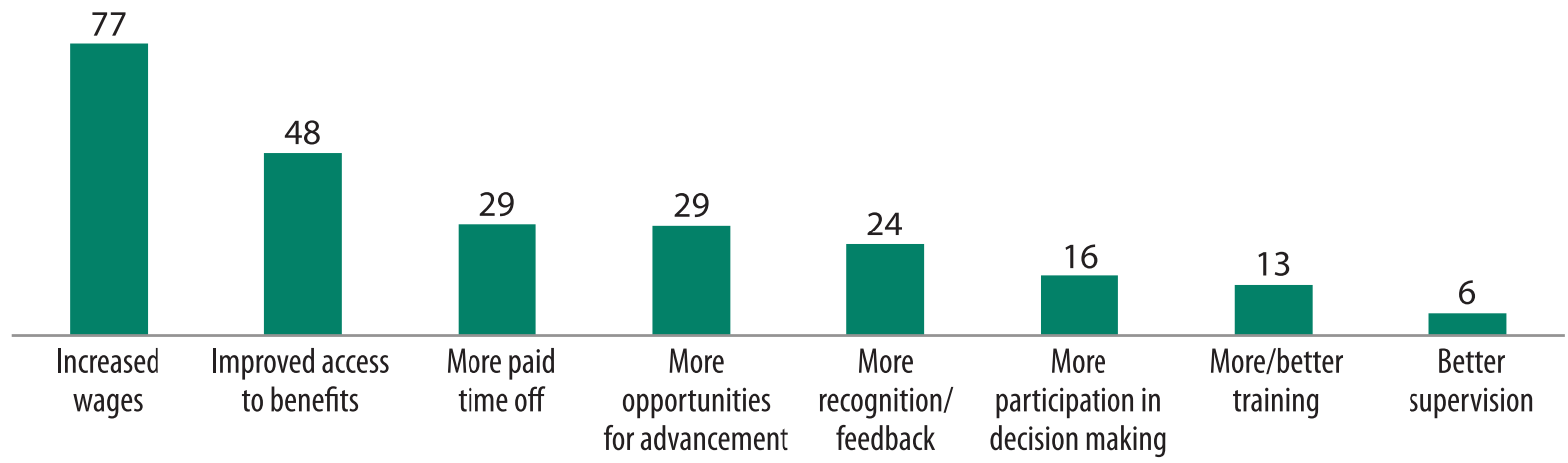

reimbursement rate in June 2008 was $\$ .505$ per mile, and in July 2008 it jumped up to $\$ .585$ per mile. Among those agencies who reimbursed for mileage, there was a wide range (between $\$ .25$ per mile and $\$ .585$ per mile), and the average reimbursement rate was $\$ .49$ per mile. However, when considering all agencies, the average amount reimbursed for mileage was $\$ .41$ per mile, a rate that may better reflect the reality facing the home care workforce. Behind this average, we see that 40 percent of all agencies reimbursed at between $\$ 0.505$ and $\$ 0.585$ per mile, closely aligned with the standard federal rate at that time. In contrast, 22 percent reimbursed at a rate between $\$ 0.42$ and $\$ 0.50$ per mile, and 38 percent reimbursed at a rate lower than $\$ 0.42$ per mile or did not reimburse at all.

\section{Job Turnover}

Job turnover is a major and costly problem in the direct care industry, and New Hampshire is no exception. ${ }^{16}$ Only 13 percent of agencies state that job retention is not an issue. Fifty-three percent acknowledge turnover as a minor problem, and 35 percent state it is a somewhat serious or a serious problem. Further, 81 percent state they need to hire one or more home care workers to meet service demands. Agencies are more likely to report workers leaving their agency (92 percent) than joining ( 86 percent) in the prior 12 months.

Turnover is costly for employers, who must recruit and train a replacement worker. With paid caregivers, turnover means a lack of continuity in care for the care recipient. Low wages are linked to high turnover in the direct care profession. ${ }^{17}$ Improving the quality of these positions through increased wages, benefits, and working conditions is key to recruiting and maintaining a quality direct care workforce. ${ }^{18}$ This message is loud and clear from one home care worker: "To improve this job they need to provide full-time work with benefits. If they can't get the work at a full-time level, they get a smaller paycheck and no benefits. They move on."

\footnotetext{
"To improve this job they need to provide full-time work with benefits. If they can't get the work at a fulltime level, they get a smaller paycheck and no benefits. They move on."

-PCSP, 46-year-old with some college education
}

Although we cannot directly analyze turnover with our survey, we can compare those who have worked with an agency for several years with those who are new to the agency to gain insights on those workers who remain with their agency.

On average, home care workers have worked with their agency for 41 months. Many, of course, have worked in the home care field for much longer but for various reasons have not stayed with the same agency. Homemakers and LNAs have worked with their current employer longer than PCSPs. Full-time workers have worked for their agency for 66 months, on average, with more than one-half working there for four or more years. This is much longer than part-time workers, who on average have worked with their agency for 31 months.

As noted, workers with seniority are more likely to have workplace benefits, such as paid sick days, paid vacation days, or earned time. However, they are not more likely to have health insurance. 


\section{How to Improve Home Care Work and Reduce Turnover}

Research links high turnover to lower-quality services and care and negative effects on those receiving care. Improving the quality of these paid care-giving positions through higher wages, expanded benefits, and better working conditions is key to recruiting and maintaining a quality home care workforce. ${ }^{19}$

\section{Wages}

Although raising the minimum wage is a frequent policy recommendation, even a large increase of the minimum wage by $\$ 1$ per hour would only directly increase the wages of 9 percent of home care workers in New Hampshire. Another option is to examine the state's Medicaid reimbursement structure to ensure that home care workers receive a livable wage and have access to benefits, such as health insurance and paid leave, through the establishment of a rational rate-setting process and a reimbursement incentive structure based on benchmarks (refer to NH Coalition for the Direct Care Workforce, endnote 5, for more details).

Although gas prices have declined since the summer of 2008 (when this survey was in the field), reimbursement for mileage is still important to decrease work-related expenses among the home care workforce. Pegging mileage reimbursement rates to the federal rates would reduce work costs for many, particularly for those in agencies that do not pay any mileage reimbursement.

\section{Steady, Full-time Employment}

Among the 71 percent of home care workers who do not work full-time at their direct care agency, many desire more hours and take on a second job to make ends meet. Their part-time status often makes them ineligible for health insurance coverage and cuts in half their likelihood of having paid leave. Increasing work hours to full-time for those who want more hours could improve job quality, increase takehome pay, and improve access to benefits.

\section{Health Insurance and Paid Leave Benefits}

The primary reason given for not having health insurance among the uninsured is that the employee premiums are too expensive. For a home care worker earning $\$ 10$ per hour, paying $\$ 613$ per month for family coverage is out of reach. Therefore, considering ways to lower out-of-pocket costs among the home care workforce would go a long way to improve job quality. In addition, exploring the means for employers to reduce the overall cost of family health insur- ance, as their monthly contribution is high as well, could infuse cost savings. One option for making health insurance more affordable is to include funding for insurance in the Medicaid reimbursement rate, with the increased reimbursement only to be used to purchase an affordable health insurance plan.

Two-thirds of home care workers do not have any paid leave benefits. This becomes particularly troublesome in the event that they become sick and forces a hard decision: stay home and lose wages or possibly even your job, or go to work sick and put the health of your clients at risk. Some workers expressed concern about taking time off because there was no one else to provide care for their clients. Having a pool of competent replacement workers to fill in during paid time off would ensure quality care, reduce contagion, and decrease burnout.

\section{Opportunities for Advancement}

Finally, creating ladders for advancement within the direct care profession and the home care agency can improve the quality of these professions. Not all home care workers seek to become nurses, so creating opportunities within the direct care occupation is useful. Increased training, peer mentors with additional pay and responsibility, and tuition supports to encourage workers to pursue an LNA license could provide opportunities for advancement.

\section{Conclusion}

If New Hampshire is serious about its desire to reduce turnover among the home care workforce, meet the projected needs of the aging population, and provide the quality care necessary to help keep Granite Staters in their homes as they age, then the road map is clear and adeptly articulated by the home care workers themselves: increase wages, increase hours, increase access to health insurance and paid leave, and increase opportunities for advancement.

\section{Data}

The data for this brief come from the New Hampshire Direct Care Workforce Survey, developed in partnership between the Carsey Institute, the New Hampshire Institute for Health Policy and Practice, the New Hampshire Coalition for the Direct Care Workforce, and the University of New Hampshire Survey Center and funded by the Administration on Aging-Aging and Disability Resource Center (AoA-ADRC) project. During the summer of 2008, researchers surveyed employers and employees of home care agencies that provide 
home and community-based services and received reimbursement from Medicaid, Medicare, and other federal and state funded programs. Researchers identified sixty-one agencies to survey. One refused to participate. Of the sixty remaining agencies, thirty-eight completed the agency survey, resulting in a response rate of 63 percent.

For the employee survey, researchers drew a stratified random sample of one-third (20) of all agencies and distributed surveys to 2,029 workers. Stratification was based on agency size. Researchers administered the employee survey through the agencies, given that employee lists were unavailable. Among the employees, 579 completed surveys for a response rate of 29 percent. Researchers sent several reminders in employee paychecks and raffled twenty gas cards worth $\$ 100$ each to boost response. Data presented are not weighted. Data on the New Hampshire workforce come from the 2007 American Community Survey (ACS) analyzed by the author.

\section{Endnotes}

1. Ross Gittell, "New Hampshire's Aging Population and Changing Economy," presentation at Leadership New Hampshire 2006 conference, retrieved from http://www.leadershipnh.org/ nhleadersdemographics4-3-06.ppt.

2. Carsey Institute, "Northern New England Indicators, New Hampshire: Age," Carsey Institute, University of New Hampshire, http://nneindicators.unh.edu/ ShowOneRegion.asp? IndicatorID=5\&FIPS=33000.

3. American Association of Retired Persons, "Long-Term Care in NH. A Survey of AARP Members" (Washington, DC: Knowledge Management, 2003).

4. R. Mollica, E. Kassler, L. Walker, and A. Houser, "Taking the Long View: Investing in Medicaid Home and Community-Based Services in Cost Effective" (Washington, DC: AARP Public Policy Institute, 2005).

5. NH Coalition for the Direct Care Workforce, "Strategies for Investing in New Hampshire's Direct Care Workforce,” 2009.

6. New Hampshire Department of Employment Security, "New Hampshire Employment Projections by Industry and Occupation" (Concord, NH: DES, 2008), available at http://www. nh.gov/nhes/elmi/pdfzip/econstat/projections/proj06-16/ Projections2006-2016.pdf.

7. Paula England, M. Budig, and Nancy Folbre, "Wages of Virtue: The Relative Pay of Care Work," Social Problems 49(4) (2002): 455-473.

8. Kristin Smith and Reagan Baughman, "Caring for America's Aging Population: A Profile of the Direct-care Workforce," Monthly Labor Review 130(9) (2007): 20-25.

9. Bernadette Wright, "Direct Care Workers in Long-Term Care" (Washington, DC: AARP Public Policy Institute, 2005).

10. Paraprofessional Healthcare Institute, "Facts 3: Who Are Direct-Care Workers?” (Bronx, NY: PHI, 2009), www.directcareclearinghouse.org/download/ NCDCW\%20Fact\%20Sheet-1.pdf.

11. The survey results confirm that these models are working as expected-PCSPs are more likely to care for friends and neighbors than LNAs and homemakers.

12. The Bureau of Labor Statistics (BLS) reports that home health aides in New Hampshire earn a median wage of $\$ 10.97$ per hour. The small discrepancy is likely owed, in part, to the inclusion in BLS figures of home health aides who work in hospitals and nursing homes, industries that pay higher wages than home care settings. In addition, the study's sample includes only agencies that the state reimburses for Medicaid, which likely pay lower wages. 
13. The 2008 livable rates are calculated by applying the Consumer Price Index (CPI) for the Northeast region to the 2007 livable wage rates produced by Daphne Kenyon and Allison Churilla, "Many New Hampshire Jobs Do Not Pay a Livable Wage," Issue Brief No. 10 (Durham, NH: Carsey Institute, University of New Hampshire, 2008).

14. This calculation is based on $\$ 10.25$ for 40 hours for 50 weeks. Recall that only 29 percent of home care workers have full-time positions.

15. Kristin Smith and Reagan Baughman, "Low Wages Prevalent Among Direct Care and Child Care Workforce." Policy Brief No. 7 (Durham, NH: Carsey Institute, University of New Hampshire, 2007).

16. D. Seavey, "The High Cost of Frontline Turnover in Long-Term Care" (Washington, DC: Better Jobs, Better Care, Institute for the Future of Aging Services, 2004); Paraprofessional Healthcare Institute and North Carolina Department of Health and Human Services, "Results of the 2003 National Survey of State Initiatives on the Long-term Care Direct-Care Workforce" (New York: Paraprofessional Health Care Institute, 2004).

17. Smith and Baughman, “Caring for America’s Aging Population."

18. S. Dawson and R. Surpin, "Direct-Care Health Workers: The Unnecessary Crisis in Long-Term Care” (New York: Paraprofessional Health Care Institute, 2001).

19. Ibid.

\section{A C K N O W L E D G M E N T S}

The author thanks Laura Davie and Kim Persson at New Hampshire Institute for Health Policy and Practice; Mary Maggioncalda at the New Hampshire Department of Health and Human Services; Alex Olins and Carol Regan at PHI; Susan Young at the Home Care Association of New Hampshire; Susan Fox at the Institute on Disability at the University of New Hampshire; Mil Duncan, Erin Trainer, and Amy Sterndale at the Carsey Institute; and Barbara Ray at Hired Pen for their thoughtful comments and suggestions. Research assistance was provided by Siobhan Whalen and Kristi Gozjolko.

\section{ABOUT THE AUTHOR}

KRISTIN SMITH is a family demographer at the Carsey Institute and research assistant professor of sociology at the University of New Hampshire.(kristin.smith@unh.edu) 


\section{UNIVERSITY
of NEW HAMPSHIRE}

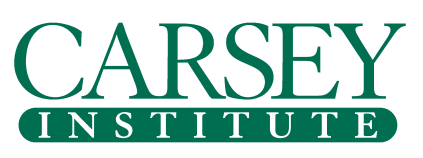

Building knowledge for families and communities

The Carsey Institute conducts policy research on vulnerable children, youth, and families and on sustainable community development. We give policy makers and practitioners timely, independent resources to effect change in their communities.

This policy brief was supported in part by the New Hampshire Institute for Health Policy and Practice and the Institute on Disability at the University of New Hampshire; the Aging and Disability Resource Center Grant sponsored by the Administration on Aging and Centers for Medicare and Medicaid Services; and the Systems Transformation Grant sponsored by the Centers for Medicare and Medicaid Services. However, the contents do not necessarily represent the policy of the U.S.

Department of Health and Human Services, and readers should not assume endorsement by the federal government.

\section{G.}

This piece is printed on Mohawk 100\% recycled paper, which is manufactured entirely with Green-e certified wind-generated electricity.
Huddleston Hall

73 Main Street

Durham, NH 03824

(603) 862-2821

www.carseyinstitute.unh.edu 